\title{
«Puntos de fuga» en Carara: Convivencia y construcción social del porvenir
}

\author{
Diego Lobo Montoya*
}

\begin{abstract}
RESUMEN
Este artículo procura comprender y visualizar los procesos auto-eco-reorganizativos de la sociedad en su verdadera dimensión y potencial. Para esto, se muestran algunos ejemplos presentes en la realidad social de Carara y se entretejen sus relaciones orgánicas con una propuesta sistémica y bioética más amplia. Se sostiene que algunas de las cualidades encontradas en la realidad de Carara constituyen verdaderas fuerzas autopoiéticas que pueden establecer «puntos de fuga» para refundar lo microsocial con perspectiva planetaria.

Palabras clave: convivencia, auto-eco-re-organización, discusión pública, concertación, punto de fuga.

\section{ABSTRACT}

This article seeks to comprehend the processes of eco-self-organization of society in its true potential. Thus, this article discusses some examples in the reality of Carara and its organic connections with a broader bioethical and systemic approach. Some of the qualities found in the rural societies of Carara are true autopoietic forces that have the power to establish "vanishing points" to reconstruct local society in a planetary perspective.
\end{abstract}

Keywords: living together, eco-self-organization, public discussion, social agreement, vanishing point.

\section{Preámbulo}

Aquí yace una parte de las reflexiones surgidas en el marco de la investigación de tesis denominada «Sistema, ecología y comunidad: una aproximación antropológica en las montañas de Carara». Esta se realizó en el marco de la licenciatura en antropología social de la Universidad de Costa Rica en el período 2006-2007, y se ubicó en una región montañosa del Pacífico Central de Costa Rica conocida como Carara.

En la investigación de origen, se procuró constituir un enfoque que, a la vez de antropológico fuese sistémico, ecológico y convivencial, y por tanto, este texto constituye sólo un componente

\footnotetext{
* Diego Lobo Montoya. Costarricense. Licenciado en Antropología Social. Consultor independiente, diegolobom@gmail.com
} 
dentro de la perspectiva desarrollada. Como tal, le corresponde entretejer y complementar parte de las dimensiones empírica/experimental y epistemológica/conceptual, como vía para comprender holísticamente la realidad de estudio. El campo específico que desarrolla es la búsqueda de elementos que replantean-como mecanismos autoinstituyentes-lo concerniente a la convivencia social como un proyecto en marcha.

Para profundizar aun más en el contexto y sentido de la propuesta como una totalidad, se recomienda acudir a la investigación originaria. He aquí, entonces, una proposición de comprender la vida social en Carara como un proceso autopoiético.

Existen cosmovisiones que tienden a re-vincular lo social con lo ecológico a través de sentidos de pertenencia (al oikos ${ }^{I}$ ) y de responsabilidad (ante la respublica ${ }^{2}$ ). Estos hechos podrían verse como nodos aislados, como conclusiones privadas y recogidas de algunos solitarios. Sin embargo, también pueden verse como una construcción comunitaria, reflexiva y convivencial. La primera opción nos deja a merced del pesimismo y la displicencia; la segunda nos permite revitalizar neguentrópicamente 3 la relación y devolver dignidad al gran milagro de la vida.

Siguiendo a Morin (1995), estas tendencias pueden servir como «puntos de fuga» para salir del micromundo insular del maquinismo y volver a ser parte del mundo, parte de la auto-eco-reorganización, parte de la gran ecosociedad de la era planetaria. Si se miran de esta manera, estas cosmovisiones no son sólo abstracción sino que son tendencias reflexivas producidas a través de la constante renovación de la cultura y la vida social.

Con su inserción en la microesfera pública (Olvera, 1999), es decir, en los momentos de reflexión y discusión comunitaria, pero también a través de la educación y la acción pública, las mismas pasan a ser, poco a poco, asuntos de influencia y dominio público, pero también espacios de solidaridad, identidad y convivencia.

Este tipo de cosmovisiones que replantean aspectos de la vida social se hallan dispersas a lo largo y ancho de todos los rincones de Carara. En cada pueblito perdido en la montaña se puede encontrar alguna persona que discuta y reflexione, algún signo que interrogue al transeúnte, algún huerto en donde juegan los niños en busca de frutos o algún rinconcito de bosque protegido en dónde se mantiene la vida natural y cantan las $\operatorname{coicotas}^{4}$ :

"bueno uno a través de los años va viendo y conversa con alguna gente que si no cuidamos lo poquito que hay,

\footnotetext{
${ }^{1}$ En griego, "hogar".

${ }^{2}$ En latín, respublica es una conjunción de dos palabras: res + publica, que significan literalmente "asunto público". Para Chantal Mouffe, este concepto implica una idea de comunidad política en el sentido de vínculo ético que permite garantizar a todos los ciudadanos un trato como personas libres e iguales.

${ }^{3}$ Este término proviene de neguentropía, que es el principio opuesto a la segunda ley de la termodinámica (la entropía). Propuesto por Erwin Schrödinger, la neguentropía es la fuerza que tiende a crear mayores niveles de orden en los sistemas abiertos.

${ }^{4}$ Coicota es el nombre local utilizado para todos los pájaros de la familia Trogonidae.
} 
y siquiera que cuidemos, porque sembrar, casi es raro el que se pone a sembrar, a mí me gusta, lo de sembrar y cuidar"

[testimonio de agricultor de Carara, 2006]

Estamos entonces ante la conjunción de varios factores beneficiosos que potencian procesos de reformulación de la convivencia. Estos son: 1) una identificación creciente del vínculo entre lo medioambiental y lo humano, con raíces histórico-culturales; 2) una reflexión local en la microesfera pública sobre el deterioro de la relación y sus consecuencias negativas; 3) una tendencia hacia la ponderación de alternativas de convivencia social y ecosistémica; 4) el surgimiento de organizaciones de gestión comunitaria; 5) la creación de pequeños proyectos productivos alternativos y sostenibles y; 6) la conciencia de la situación de crisis inminente del medio ambiente global y la urgencia de introducir cambios.

La existencia misma de estas tendencias es ya un gran paso y una fuente de inspiración y optimismo para nuestras causas. Sin embargo, por su misma naturaleza, estas tendencias desembocan en la proposición de alternativas para la sociedad local, y porqué no, para la sociedad en general. ¿Qué quiere decir esto? Pues que la existencia de esferas públicas en dónde tenga cabida el pluralismo y la autorreflexividad social, como lo señalan Olvera (1999) y Thoenig (1997), desemboca naturalmente en la generación de iniciativas y acción pública, es decir, en procesos de co-construcción política y cultural de la sociedad.

¿Cuál es la naturaleza de las propuestas en la realidad que nos ocupa? Aquí se sostiene que son principios auto-eco-re-organizativos o autopoiéticos ${ }^{5}$ ya que introducen variaciones en el sistema social que intentan reconstruir el equilibrio perdido en la interacción con el resto de los sistemas vivos, y por supuesto con el sistema social mismo.

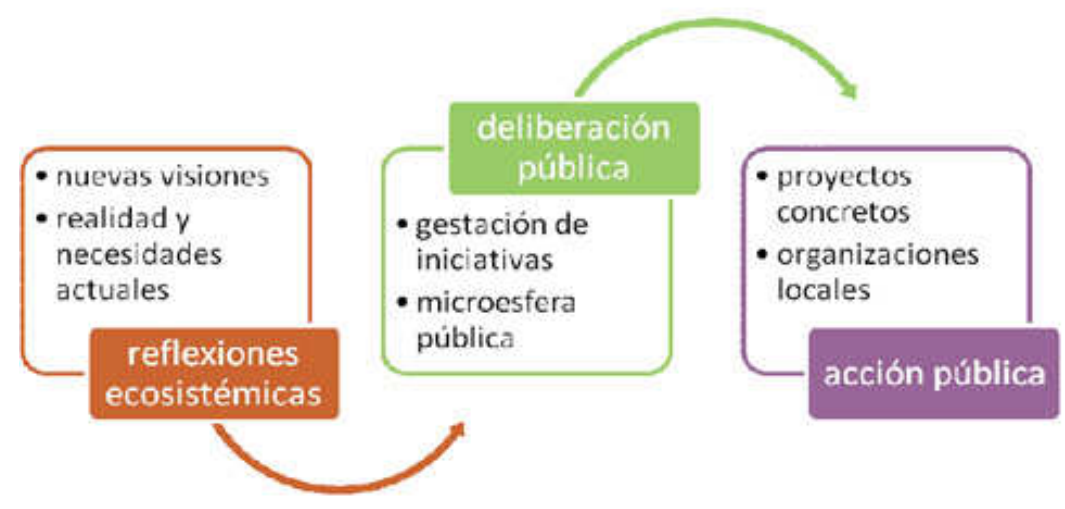

\section{Ilustración 1. Lógica de los procesos de reinvención social en Carara.}

\footnotetext{
${ }^{5}$ Ambos conceptos pueden entenderse como sinónimos. Para Maturana y Varela (2003), la autopoiesis se puede definir como "la organización de lo vivo": es la propiedad de los sistemas vivos de autocrearse y de generar -en un proceso continuo- las condiciones esenciales para su subsistencia y su reproducción.
} 
En la realidad comunitaria de Carara se ha observado que el flujo del proceso de las tendencias autopoiéticas surge de las reflexiones sobre la vida cotidiana y la necesidad de replantear lo vital ante la desestructuración del modelo de producción agropecuaria y la creciente evidencia de que la nueva senda debe armonizar con el medio ambiente. De esas reflexiones introspectivas el asunto se traslada al dominio de lo público y la convivencia por lo cual se convierte en tema de charla, discusión, colectivización y gestación de ideas. Luego de esto se llega naturalmente a la proposición de iniciativas y proyectos concretos como respuesta ante la incertidumbre.

Por supuesto que esta lógica no está escrita en piedra, ni sigue el curso según un esquema preestablecido. La esquematización es una forma de abstraer lo que indica la evidencia y, por tanto, un enfoque que se cree adecuado para comprender el proceso de interés. Veamos el mismo esquema pero esta vez haciendo alusión a hechos concretos encontrados en la realidad de Carara:

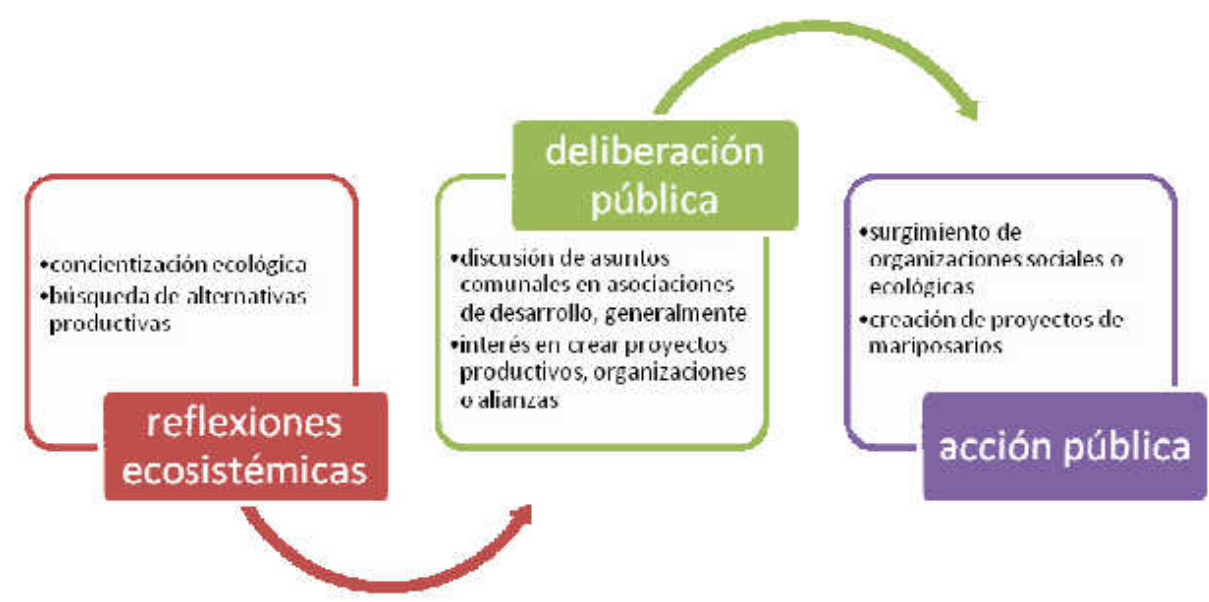

Ilustración 2. Ejemplo de procesos de reinvención social.

Estos procesos pueden verse como una relación autopoiética, es decir,

como un sistema de procesos de producción de componentes concatenados de tal manera que producen componentes que: i) generan los procesos (relaciones) de producción que los producen a través de continuas interacciones y transformaciones, y ii) constituyen a la máquina como una unidad en el espacio físico. Por consiguiente, una máquina ${ }^{6}$ autopoiética, especifica y produce continuamente su propia organización a través de la producción de sus propios componentes, bajo condiciones de continua perturbación y compensación de esas perturbaciones (producción de componentes). (Maturana y Varela 2003: 69)

\footnotetext{
${ }^{6}$ Según Humberto Maturana y Francisco Varela, las «máquinas» son unidades que "están formadas por componentes caracterizados por ciertas propiedades capaces de satisfacer ciertas relaciones que determinan en la unidad las interacciones y transformaciones de esos mismos componentes" (Maturana y Varela 2003: p. 67).
} 
Según esta visión, cada proceso de la reinvención social particular, ya sea la concientización ecológica o la creación de un mariposario, produce su propia dinámica a la vez de contribuir a la producción de las demás dinámicas y el desarrollo general de reinvención sociocultural. ¿Esto qué quiere decir? Pues que, en otras palabras, la reinvención social, en cualquier lugar pero por el momento en la realidad de Carara, es una realidad viva que ha sido capaz de mantener la cultura misma del ser humano, su identidad y la hominización como una constante general a lo largo de la historia y el devenir humano. Aunque puede sonar redundante o extraño, es importante comprender el sentido planetario de los procesos microsociales para poder analizarlos como lo que verdaderamente son: elementos de recreación de la vida social y la cultura humana.

En la geométrica descriptiva, la arquitectura y el dibujo, existe una noción que nos puede ayudar a comprender poéticamente la

- Reflexión:

- "si aquí no cxisticra esta rescrva [Parque Nacional Carara] que son cinco mil hectáreas, más las partes que hay privadas que podrán ser unas cuatro mil más, diay si no existiera eso, diay, cómo podría ser aquí, diay seco, no llovería, porque aquí la gente sabe que llueve porque está el parque y las reservas, la gente está consciente de que aquí llueve más que en Jacó porque tenemos esta montaña aquí a la par $^{\prime \prime}$

- Participación pública:

- Activista del medio ambiente y la comunidad desde hace unos quince años. Es to le ha cons truido fama de ecologista, incluso ante los

funcionarios del $P$ arque $\mathbf{N a c i o n a l , ~ o r g a n i z a c i o n e s ~ c o m u n i t a r i a s , ~}$ empresas turís ticas y comunidades aledañas. Gracias a esto, ha mantenido un trabajo estable y bien remunerado en el área turística, una creciente inspiración y convicción en sus causas y un sólido activismo local. Aunado a eso, posee una pequeña finquita y siembra varios cultivos en pequeña cantidad y de forma tradicional para el auloconsumo familiar.

- Acción pública:

- La experiencia acuñada por este señor es reconocida en toda la comunidad, pero su influencia no queda ahí. Su participación en la vida pública es actlva y durante varios ahos ha formado parte de asociaciones y comités locales, además mantiene muy buenas relaciones con los funcionarios del Parque, los empresarios turísticos y otros líderes comunales.

\section{Tendencia de acción pública}

\section{En Bijagual de Carara} verdadera dimensión de estos procesos. En estas disciplinas se habla de «punto de fuga» ${ }^{7}$ como la representación del infinito a través de una proyección cónica. Todas las líneas paralelas o tendencias convergen en el horizonte, en un mismo punto de fuga. Sin importar su procedencia (o su posición en el plano) todas las líneas paralelas convergen en el horizonte y de alguna manera fusionan su esencia misma.

¿Podría comprenderse así la existencia del pluralismo? ¿Se puede apuntar al bien colectivo armonizando la diversidad? Si se suman las múltiples visiones que entretejen orgánicamente la pertenencia al oikos y la responsabilidad ante la respublica, algunas causas comunes pueden ser verdaderos puntos de fuga, umbrales prácticos, filosóficos y éticos que replantean lo social en función de la convivencia, como arte y poesía.

Otro complemento en este sentido sistémico-constructivista lo pone el antropólogo social suizo Andreas Wimmer (2000) quien plantea una concepción de la cultura como concertación. Al poner el acento en la convivencia, Wimmer sostiene que la cultura se entiende como un proceso abierto e inestable de la negociación de significado. De esta forma, lo cultural deja de ser un anclaje fijo e inmutable, para convertirse entonces en el ámbito en dónde la sociedad negocia y recrea perspectivas y significados de forma plural y abierta.

\footnotetext{
${ }^{7}$ Escuela Técnica Superior de Arquitectura de Madrid, España. Ideación gráfica arquitectónica. Recuperado el 2 de noviembre del 2007 desde: http://www.aq.upm.es/Departamentos/Ideacion/asignatura/descriptiva/descriptiva.htm
} 
Para Wimmer, "Lo que hace posible que los seres humanos transformen ese paisaje y viajen dentro de él es la capacidad universal de hacer que el significado y el interés percibido concurran. Me gustaría denominar ese proceso «la pragmática de la producción cultural»". (Wimmer, 2000: 148) En cierta forma, estos planteamientos se complementan con las nociones de acción comunicativa, entendimiento y acuerdo de Habermas (1981) al confluir en la importancia de la vida pública como mecanismo de reformulación de lo socialcultural.

Wimmer también considera los fenómenos netamente "culturales" como espacios de negociación y recreación social:

Tanto si tiene lugar en nuestro mercado de medios cacófonos de comunicación como en la plática relajada en el diván de una aldea kurda; tanto si es el murmullo de voces de una reunión en una comunidad indígena de México como en una serie de conferencias académicas, siempre hay por lo menos un motivo discernible: el intento de establecer el punto de vista propio sobre el mundo como una perspectiva válida y así formar el mundo de acuerdo con las ideas propias. Como esto sólo puede lograrse si otros aceptan y comparten el punto de vista propio sobre el mundo, la formación de una concertación cultural es el objetivo implícito de la pragmática de la producción cultural y la negociación del significado resulta obviamente de importancia fundamental para lograrlo. (Wimmer, 2000: 148)
*Reflexión:

- "Hay que valorar lo propio. Aquí lo que hay es montaña y tradición y ron eso queremos vivir nosotros. Nosotros tenemos una tierrita para sembrar el consumo propio y también para cuidar, que es muy importante".

-Participación pública:

- Participación familiar en organizaciones comunales como Asociación de Desarrollo, comité escolar, comité de la iglesia, comité de acueductos y caminos, entre otros. Creación de proyecto turístico local repartido entre la familia. La mujer es reconocida como líder comunal muy positiva.

- Acción pública:

- Gestación de un proyecto de turismo rural de varios componentes distribuidos equitativamente entre toda la familia, por ejemplo: mientras uno brinda una cabalgata por la montaña, otro ofrece un "canopy tour", otro se encarga del transporte, y así sucesivamente. La encr gada y coordinador del proyer:lo es una joven mujer

emprendedora que, junto a su esposo, imaginaron el proyecto desde el comienzo de su matrimonio. Esta mujer además es dueńa de una soda que formaría parte del circuito turís tico y en la actualidad brinda un excelente servicio de comidas tradicionales como: picadillos de palmito, zorrillo, raíz de papaya, flor de pacaya, flor de tococa y chicasquil, tortillas tradicionales, carnes, casados acompañados de platillos criollos y dulces y mieles de frutas, utilizando en gran medida productos de las fincas familiares o de algunos vecinos. Su proyecto aún no se completa, pero demues tra carisma, solidez y cariño.

\section{Tendencia de gestión y} organización comunitaria

\section{En Bijagual de Carara}

\section{-Reflexión:}

- "después de que yo empecé a tener los carajillos yo vi que, o sea que siquiera yo, el país iba por mal camino porque diay tanta tala de árboles, después yo pensé que había que ruidar lo poquito que uno tenía, si no podía uno hacer que otro cuidara, cuidar lo poquito de uno porque, es que no, es una lástima como se botaba árboles y hoy día se sigue botando así desconsideradamente, y seguro que eso me llevó a mi a pensar ya en los carajillos, diay, que no podiamos dejarle esta tierra, que es tan bonita, de viaje sin nada de árboles"

-Participación pública:

- Familia cofundadora de la comunidad. Han sido ejemplos de conciencia ecológica y comunitaria ya que han participado a lo largo de muchos años de organizaciones locales como la Asociación de acueducto, la Asociación de desarrollo comunal, las asociaciones de la escuela y la iglesia y, como si fuer a porn, del coro de la iglesia también. Además de esto, las familias tienen huertos donde cultivan productos tradicionales para el autoconsumo familiar y siempre han mantenido viveros con especies frutales, plantas ornamentales y árboles nativos de los bosques cercanos.

- Acción pública:

- Participación en dos intentos de organización comunitaria, ecológica y productiva, uno en el año 2003 y otro más reciente en el año 2006 Recientemente montaron un pequeño mariposario orientado a la venta de pupas para la exportación. El trabajo cotidiano del mariposario es realizado en su totalidad por las mujeres y los niños y niñas con gran destreza, mística y conocimiento. Además de ser una actividad productiva complementaria para ambas familias, la inler acción y el Ir ahajo conjumlo ha mejor ado asper:los de Ia convivencia familiary, al ser una actividad tan agradable, permite el esparcimiento, la admiración de la naturaleza y la reflexión sobre la vida.

Tendencia de gestión y organización comunitaria En San Isidro de Carara

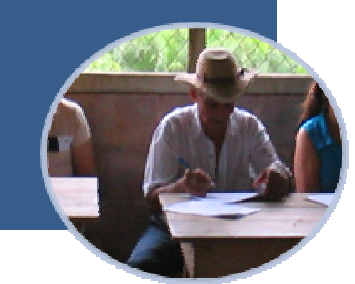

108 
En Carara existen varias morfologías discretas que están indicando la existencia de corrientes diversas de dignificación de la vida social en armonía con la vida natural. Como se señaló anteriormente, estas tendencias surgen en primera instancia como reflexión y preocupación bioética (ecosistémica). Según la propuesta de Wimmer, podríamos también establecer que, como fundamento de estas corrientes, encontramos producción cultural, es decir, hallamos en su génesis la cultura como proceso vital del sistema social.

Según Morin, la cultura, comprendida en un sentido como este, se articula perfectamente con el sistema social en su conjunto y las condiciones más amplias del sistema ecológico planetario:

Esta concepción permite concebir la relación hombre-sociedad-mundo que mantiene $y$ define una cultura a través de los relés polarizadores y transformadores, el código y la pattern, que constituyen cada uno de los complejos subsistemas en el interior del sistema (...) Así, la cultura, en nuestra sociedad, es el sistema simbióticoantagonista de múltiples culturas, cada uno no homogéneo. (Morin, 1995: 147, 148)

Lo que es importante aquí es rescatar que los procesos de reflexión ecosistémica / discusión pública / acción pública no solamente actúan a través de las esferas públicas y el ámbito político sino también a través de la cultura ya que aquí

el doble fenómeno de la unidad y de la diversidad de las culturas es crucial. La cultura mantiene la identidad humana en lo que tiene de específico; las culturas mantienen las identidades sociales en lo que ellas tienen de específico. Las culturas están aparentemente encerradas en sí mismas para salvaguardar su identidad singular. Pero, en realidad, también son abiertas: integran en ellas no solamente saberes y técnicas sino también ideas, costumbres, alimentos, individuos provenientes de otras partes. (Morin, 1999: 29)
- Reflexión

- Cuando formaron la familia se vinieron a vivir al borde del bosque, ahí: "La montaña es lo más bello que puede haber". Desde niño, -recuerda-, le encantaba perderse en las fincas de su padre en playa Herraduray, según dice, en aquel tiempo sólo le bastaba estirar el brazo para agarrar de "las barbas" a las grandes langostas y llegar con orgullo ante su madre con comida fresca para todos. De joven fue todo un monteador pero la culpa no lo dejó seguir y un día tuvo que dejarlo para siempre y convertirse en su guardián sempiterno.

- Participación pública:

- Defensa del medioambiente en numerosas ocasiones, denuncias de tala y cacería ilegal, reforestación y conservación de sus propiedades, participación en organizaciones de medio ambiente y producción agrícola orgánica y a la usanza antigua.

- Acción pública:

- Toda una vida en la función de guardaparques, fundación de Comité de Vigilancia de Recursos Naturales (COVIRENA), creación de organización de productores locales, numerosos contactos e iniciativas

Tendencia de acción pública

En El Barro de Turrubares

Precisamente, estas tendencias autopoiéticas presentes en Carara son, a la vez, de procesos político-sociológicos también procesos del sistema cultural que fomentan la refundación de lo microsocial a partir de ejes basados en nuevas éticas convivenciales formuladas en la misma micro-esfera pública local. Una vez que se ha reconstruido un enfoque eco-sistémico de lo social, 
comienzan a surgir rasgos verdaderamente enriquecedores para la vida social local. Éstos replantean las formas en las cuáles se interpretan las condiciones esenciales de la libertad y la igualdad, pero también del sentido ético de la vida humana en Carara y, esperamos, mucho más allá: "El hombre prosaico es también el de la poesía, es decir del fervor, de la participación, del amor, del éxtasis. El amor es poesía. Un amor naciente inunda el mundo de poesía, un amor que dura irriga de poesía la vida cotidiana, el fin de un amor nos devuelve a la prosa." (Morin, 1999: 29)

Con poesía, como Arne Næss y James Lovelock, pero también como Leonardo Boff cuando habla del surgimiento sorpresivo de un ethos ${ }^{8}$ humano y planetario, se puede llegar a la conclusión de que el nacimiento de culturas, tradiciones y formas de reinvención identitaria con vasto y firme arraigo, son conclusiones importantísimas en aras de refundar la vida social como subsistema de Gaia y el Cosmos.

Todos estos vínculos y relaciones han mantenido viva la esperanza de una dignificación de la vida humana junto a la vida del Gran Carara. Al compás de la dulce prosa de las verde-arboladas montañas carareñas, alguna gente ha comenzado a reforestar sus terrenos y a conservar pequeñas áreas de bosque. Alguna gente ha vuelto sus ojos y voluntad hacia los bosques y los recursos naturales. Estos cambios, no cabe duda, son principios autoinstituyentes que proponen

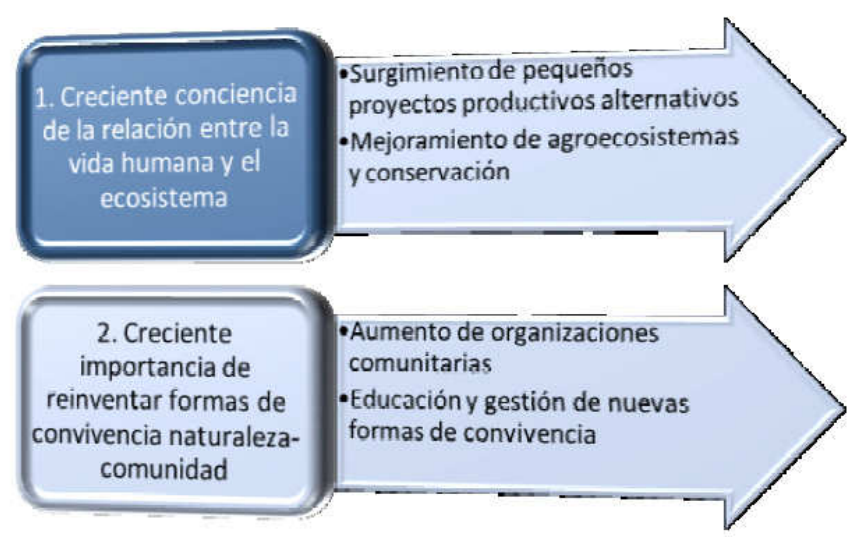

Ilustración 3. Formas de recreación (auto-eco-reorganización) de la vida social. nuevas formas de crear sociedad, comunidad y familia.

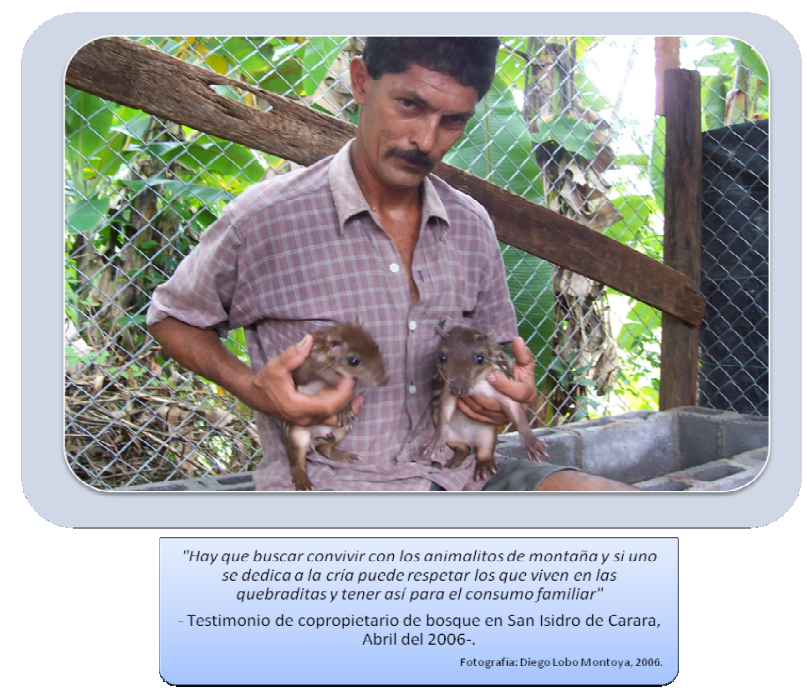

\footnotetext{
${ }^{8}$ Ethos significa, según la visión aristotélica, el hábito, carácter o modo de ser. Su origen es el mismo de la palabra griega ethikos que quiere decir «teoría de la vida».
} 
En términos poéticos se puede decir que ha reverdecido una conciencia de la relación entre la vida humana y lo ecosistémico en Carara y, gracias a ello, es posible observar el surgimiento, como semillas con las primeras lluvias, de diversos proyectos productivos alternativos y, por ende, el mejoramiento de los agroecosistemas y la conservación de los recursos naturales. Simbióticamente hay también un crecimiento en las formas de reinventar la convivencia comunidad-ecología que ha provocado un aumento considerable de organizaciones comunitarias de diversa índole, así como también, una creciente educación y gestión de nuevas formas de convivencia comunitaria y medioambiental.
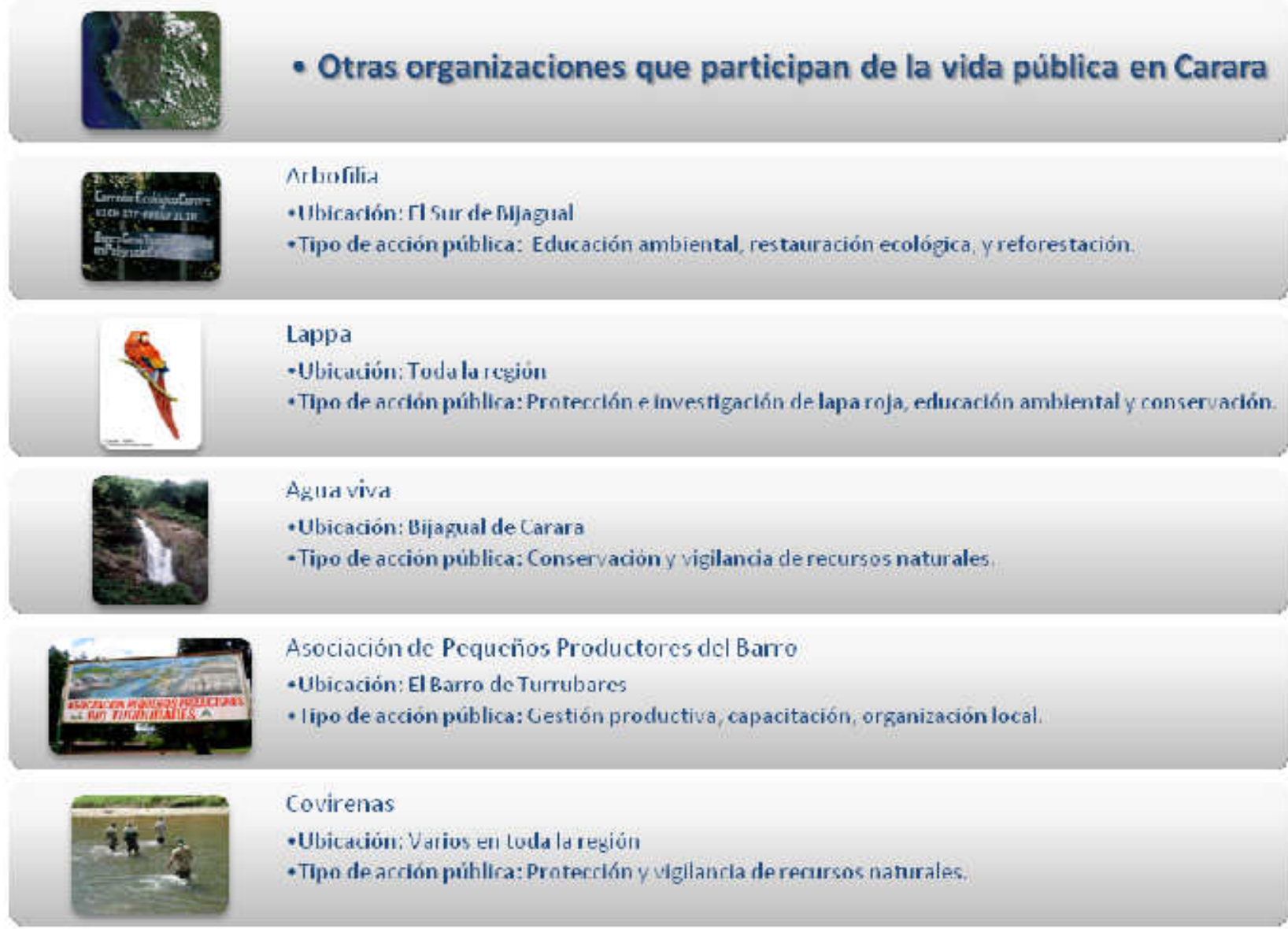

Covirenas

- Ubicación: Varios en Ludala región

- Tipo de arción púhlira: Protercí́n y uigilanria de recursos nanirales,

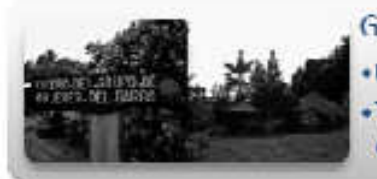

Grupode: Mujueres ded Riaro

- Ubirarión: I I liarre de I Iurmbares

- Tipo de accion pública: Educación y ges tión de género, or ganización comunitaria, reforestación v capacitación productiva.

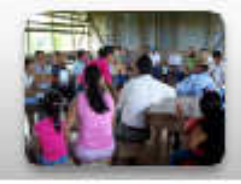

Otras organizaciones

- Ubicación: Toda la región

- Ilpo de acción pública: Desde organiraciones romunitarias, productivas, de desarrollo romunal, de iglesids, de deveductos, entie muchids otras.

\section{Ilustración 4. Elaboración propia.}


Expresiones como "el bosque es importante por cuidar la vida de uno" son evidencia de creación humana, social, política y cultural que coincide con aquello que Cornelius Castoriadis llama autoinstituir la sociedad, lo que Maturana y Varela y Niklas Luhmann llaman autopoiesis, lo que Boff llama el ethos planetario, lo que Morin llama auto-eco-re-organización, lo que Chantal Mouffe y Ernesto Laclau denominan democracia radical, en fin, nociones que son semillas fértiles en la refundación de la vida humana en una era que puede cambiar el rumbo cósmico en el pequeño planeta azul.

\section{Referencias bibliográficas}

Habermas, J. (1981). Teoría de la acción comunicativa: I. Racionalidad de la acción y racionalidad social, II. Crítica de la razón funcionalista. Madrid: Editorial Taurus.

Maturana, H. y F. Varela. (2003). De Máquinas y Seres Vivos. Autopoiesis: la organización de lo vivo. Buenos Aires: Editorial Universitaria Lumen.

Morin, E. (1995). Sociología. Madrid: Editorial Tecnos.

----. (1999). Los siete saberes necesarios para la educación del futuro. París: UNESCO.

Olvera, A. (1999). “Apuntes sobre la esfera pública como concepto sociológico”. En: Metapolítica. Revista semestral de teoría y ciencia de la política. Vol. 3 (9). pp. 69-78.

Wimmer, A. (2000). “La cultura como concertación”. En: Revista mexicana de sociología. Vol. 62 (4). 